\title{
Immunologic Detection of the Cellular Receptor for Urokinase Plasminogen Activator ${ }^{1}$
}

\author{
Ikuko F. Mizukami, Beth Ann Garni-Wagner, L. Michael DeAngelo, Monica Liebert, Andrew Flint, \\ David A. LAWRENCE, ROBERT L. COHEN, AND ROBERT F. TODD III ${ }^{2}$
}

Simpson Memorial Institute, Department of Internal Medicine, Division of Hematology and Oncology, Department of Surgery, Division of Urology, and Department of Pathology, The University of Michigan Medical School, Ann Arbor, Michigan 48109; and the Cancer Research Institute, University of California at San Francisco, San Francisco, California 94143

\begin{abstract}
The cellular receptor for urokinase plasminogen activator (uPA-R) is a monomeric phosphatidylinositol-linked glycoprotein (gp40-65) that may contribute to the invasive capacity of tumor and inflammatory cells by focusing the activity of urokinase (uPA) in converting plasminogen to plasmin, a serine protease capable of degrading extracellular matrix proteins. The further characterization of UPA-R has been facilitated by our recent development of a monoclonal antibody, anti-Mo3f, specific for uPA-R. This mAb bound to uPA-R expressed by phorbol myristate acetate-stimulated U-937 cells and by NIH-3T3 cells permanently transfected with uPA-R cDNA. In competitive binding assays, anti-Mo3f inhibited the binding of fluorescein-conjugated uPA ligand to UPA-R expressed by U-937 cells and UPA-R transfectants; conversely, preexposure of cells to saturating quantities of exogenous uPA partially blocked the subsequent binding of anti-Mo3f $\mathrm{mAb}$ to $\mathrm{uPA}-\mathrm{K}$. Anti-Mo3f $\mathrm{mAb}$ was employed as the capture reagent in an ELISA for the quantitation of soluble forms of UPA-R (derived from U-937 cells and recombinant UPA-R) which had a sensitivity of approximately 4-12 $\mathrm{ng} / \mathrm{ml}$. Anti-Mo3f $\mathrm{mAl}$ ) was also applied as a serologic probe for the detection of uPA-R expressed by human tumor tissues. By immunoperoxidase staining, anti-Mo3f demonstrated positive tumor cell staining in 4 of 16 breast and 7 of $\mathbf{3 1}$ prostate carcinomas in formalin-fixed, paraffin-embedded specimens. These data indicate that the anti-Mo3f $\mathrm{mAb}$ detects an epitope proximate to or within the ligand binding domain (domain 1) of UPA-R and may be useful as a tool for the serologic detection of $u P A-R$ in soluble form or associated with human tumors. 1994 Academic Press, lnc.
\end{abstract}

\section{INTROUUCTION}

The cellular receptor for urokinase plasminogen activator (uPA-R) is a 40 - to $65-\mathrm{kDa}$ phosphatidylinositol (PI)-linked glycoprotein that is expressed by a variety

\footnotetext{
1 This work was supported by NIH Grants CA42246 (R.F.T.), CA56973 (M.L.), HL02329 (R.L.C.), and CA44768 (R.L.C.).

2 To whom requests for reprints should be addressed at $3119 \mathrm{~N}$ Taubman Center, Division of Hematology and Oncology, University of Michigan Medical Center, 1500 E. Medical Center Drive, Ann Arbor, MI 48109-0374. Fax: 313-936-7376.
}

of human cells, including leukocytes (mononuclear phagocytes, neutrophils, and $\mathrm{T}$ cells; enhanced after exposure to inflammatory or activating stimuli), endothelial cells, hepatocytes, and certain tumor cells of both hematopoietic and nonhematopoietic origin (reviewed in 1 and 2). Since receptor-bound urokinase plasminogen activator (UPA) is catalytically active [functioning to convert receptor-bound plasminogen to the serine protease plasmin (3)] and cellular uPA content has been positively correlated with the invasive potential of inflammatory and neoplastic cells (4-10), uPA-R (in conjunction with cellular receptors for plasminogen) may serve to focus the capacity of these cells to degrade extracellular matrix during inflammatory diapedesis and metastatic invasion (reviewed in 11). Consistent with this hypothesis, pretreatment of inflammatory or neoplastic cells with antibodies specific for UPA has been shown to attenuate tissue invasion in vitro and in vivo $(4,8,9,12-16)$.

Until recently, investigation of the structure and function of the UPA-R depended exclusively on the use of ligand-binding assays. Within the past 2 years, however, we (17-19) and others $(20,21)$ have generated murine monoclonal and polyclonal antibodies specific for UPA-R. The availability of these reagents should now facilitate efforts to define the distribution of receptor expression among various normal and neoplastic cells, to dissect functional versus nonfunctional domains of the receptor, to purify large quantities of the receptor for further chemical analysis, and to assess the functional properties of the receptor in models of inflammation and tumor metastasis (in vitro and in vivo). These studies may confirm the suggestion that uPA activity found in certain human tumors (as possibly reflected by uPA-R expression) represents a clinically relevant and prognostically useful marker of invasive potential (22-26). mAb-mediated suppressive therapy of certain acute inflammatory conditions in man is also not beyond the realm of possibility. In anticipation of the broader use of anti-uPA-R reagents as probes for investigating uPA-R expression and func- 
tion, it is imperative to extend our information about the binding properties of the antibodies currently available. As described in the paragraphs that follow, we have performed serological analyses to determine the degree to which antibody and ligand compete one with another for binding to uPA-R (as expressed by U-937 cells and transfectant cell lines), to quantitate uPA- $R$ isolated in soluble form by ELISA, and to determine the extent of UPA-R expression by human tissues containing breast and prostate cancers.

\section{MATERIALS AND METHODS}

Reagents. All chemical reagents used were purchased from Sigma Chemical Co. (St. Louis, MO) unless otherwise noted. The following previously characterized $\mathrm{mAb}$ were used: anti-Mo3f mAb (clone 3B10, IgG2a) (17); anti-BMM1 mAb (anti-breast milk macrophage, clone M45, IgG2a) (27); anti-Mo1 mAb (antiCD11b, clone 44, IgG2a) (28); clone 5B7 (IgG2a) (17); anti-mouse T cell receptor $\mathrm{mAb}$ (clone KJ23; IgG1; a gift of Dr. Suyu Shu, University of Michigan) (29); and anti-epithelial membrane antigen mAb (EMA; Dako, Carpinteria, CA; reactive with breast and prostate carcinomas) (30). For certain experiments $\mathrm{mAb}$ was purified from murine ascites by Protein A-Sepharose affinity chromatography (17). Purified soluble Mo3 (sMo3) was obtained by affinity chromatography as reported elsewhere (18). Rabbit polyclonal anti-sMo3 and pooled normal rabbit serum were generated as previously described (18). Goat anti-rabbit IgG-biotin and fluorescein isothiocyanate (FITC) conjugates and streptavidin-horseradish peroxidase (HRPO) were obtained from Pierce (Rockford, IL), and goat anti-mouse IgGFITC conjugate from Calbiochem (San Diego, CA). Urokinase from human urine (uPA), predominantly of the high-molecular-weight form (HMW uPA), lowmolecular-weight uPA lacking the receptor binding domain (LMW UPA), and FITC-conjugated UPA (uPAFITC) $(25 \mu \mathrm{g} / \mathrm{ml})$ were generous gifts of American Diagnostica, Inc. (Greenwich, CT). BCA protein assay reagents were obtained from Pierce. Human gammaglobulin was obtained from ICN Biomedicals, Inc. (Costa Mesa, CA).

Production of recombinant $u P A-R$. UPA-R cDNA was cloned using RNA prepared from U-937 cells. Total cellular RNA for RT-PCR was isolated by lysis in guanidinium isothiocyanate and purified by $\mathrm{CsCl}$ ultracentrifugation. cDNA encoding full-length $\mathrm{UPA}-\mathrm{R}$ protein was then amplified using the following primers based on the published UPA-R sequence (31):

uPA-R sense (bases 36-55): 5'TTCCTCAAGCTTTTCTCTTCTGC3'

uPA-R anti-sense (bases 1221-1243): 5'GCCCTCGAGACATGGGTCAC 3 '.
The sequence of the cloned cDNA was identical to the published sequence. In a second round of PCR, a stop codon was introduced to truncate the protein after $\arg ^{281}$, deleting the putative PI-linkage site. The resulting 957-bp fragment was cloned into pCR1000 (Invitrogen, San Diego, CA), subsequently excised with $K p n \mathrm{I}$ and $N o t 1$, and recloned into the corresponding sites of the expression vector pCEP (Invitrogen) to yield pCEP/Trunc. A stable cell line secreting truncated uPA-R was obtained by transfection of 293 cells with pCEP/Trunc using the calcium phosphate method (32). Serum-free conditioned media was prepared and concentrated 10-fold on a YM-30 membrane (Amicon, Danvers, MA), and collected by affinity chromatography on uPA-Sepharose. Bound UPA-R was eluted with acid-glycine as described (10) and the neutralized eluate was concentrated using a Centricon 30 microconcentrator prior to use. SDS-PAGE followed by silver-staining showed a single broad band centered at $-50-55 \mathrm{kDa}$ which crossreacted with polyclonal antiuPA-R antiserum. In a typical experiment, $1 \mathrm{mg}$ of uPA-R could be purified from each liter of conditioned media.

Cell lines. NIH-3T3 murine fibroblasts were obtained from the American Type Culture Collection (ATCC) and cotransfected with UPA-R cDNA (19) and the cDNA for neomycin resistance (33) using the calcium phosphate method (32). Neomycin-resistant clones were screened for uPA-R expression by indirect immunofluorescence flow cytometry using anti-Mo3f $\mathrm{mAb}$ binding relative to the nonspecific binding of an isotype-identical negative control $\mathrm{mAb}$ (anti-CD11b) (19). Among the clones screened in this fashion, clones designated 3T3-1, 3T3-2, and 3T3-3 demonstrated consistent, stable UPA-R expression while clone 3T3-21 and the wild-type nontransfected cell line showed no uPA-R expression. The wild type and transfected lines were maintained as adherent cultures in Dulbecco's minimal essential medium containing high glucose and L-glutamine supplemented with $10 \%$ calf bovine serum, $50 \mathrm{U} / \mathrm{ml}$ penicillin, $50 \mu \mathrm{g} / \mathrm{ml}$ streptomycin, and an additional $2 \mathrm{mM}$ glutamine. Just prior to immunofluorescence analysis, a single cell suspension was obtained in the following manner: subconfluent cultures were washed twice with phosphate-buffered saline (PBS) and exposed to Puck's EDTA solution (5 $\mathrm{mM}$ Hepes, $136.9 \mathrm{~m} M \mathrm{NaCl}, 5.4 \mathrm{~m} M \mathrm{KCl}, 5.6 \mathrm{~m} M$ glucose, $4.2 \mathrm{mM} \mathrm{NaHCO}{ }_{3}$ anhydride, and $1.1 \mathrm{mM}$ tetrasodium EDTA) for $5 \mathrm{~min}$ followed by the addition of an equal volume of culture medium to inactivate the EDTA.

U-937 cells were obtained from Dr. Thomas Huard (University of Michigan) and maintained as suspension cultures in RPMI 1640 supplemented with $10 \%$ calf bovine serum, $2 \mathrm{mM}$ glutamine, $50 \mathrm{U} / \mathrm{ml}$ penicillin, and $50 \mu \mathrm{g} / \mathrm{ml}$ streptomycin. To enhance the surface expression of uPA-R, U-937 cells were cultured for 24 
$48 \mathrm{hr}$ in $100-\mathrm{mm}$ culture plates at a starting concentration of $0.5-1 \times 10^{6}$ cells $/ \mathrm{ml}$ in medium containing $10 \mathrm{nM}$ phorbol myristate acetate (PMA) prior to harvest for flow cytometric analysis (17).

Competitive blocking of uPA-FITC by anti-Mo3f $m A b$ and unlabeled uPA. PMA-stimulated U-937 cells and 3T3 transfectant cell lines were washed twice in cold PBS and resuspended at a concentration of $5 \times$ $10^{6}$ cells $/ \mathrm{ml}$ in wash buffer consisting of PBS containing $1 \mathrm{mg} / \mathrm{ml}$ of human gamma globulin and glucose. Aliquots $(50 \mu \mathrm{l})$ of this cell suspension $\left(2.5 \times 10^{5}\right.$ cells $)$ were dispensed into the wells of a conical bottom 96well plate and mixed with $100 \mu$ l of wash buffer containing a saturating quantity $(50 \mu \mathrm{g})$ of anti-Mo3f $\mathrm{mAb}$ (or isotype identical negative control mAb, anti-CD11), unlabeled HMW uPA (1000 ng/well), or buffer alone, and incubated for $60 \mathrm{~min}$ on ice. Then, $50 \mu \mathrm{l}$ of wash buffer containing $125 \mathrm{ng}$ uPA-FITC was added to each aliquot and the incubation continued for another 60 min. The cells were then centrifuged at $1000 \mathrm{~g}$ for 5 min at $4^{\circ} \mathrm{C}$, washed three times with $200 \mu \mathrm{l}$ wash buffer, and fixed in $200 \mu \mathrm{l}$ of PBS containing $1 \%$ formaldehyde. The relative uPA-FITC binding to the surface of the mAb- or uPA-treated cells was quantitated by flow cytometric analysis using a Coulter EPICS C flow cytometry system (Coulter Electronics, Inc., Hialeah, FL). The mean channel fluorescence (linear scale) of 10,000 cells/determination was calculated and used as a quantitative measure of relative uPA-FITC binding (19).

Competitive blocking of anti-Mo3f mAb by uPA. PMA-stimulated U-937 cells were suspended at $5 \times$ $10^{6} \mathrm{cells} / \mathrm{ml}$ in wash buffer. Aliquots $(50 \mu \mathrm{l})\left(2.5 \times 10^{5}\right.$ cells) were mixed with $100-\mu l$ quantities of wash buffer containing varying amounts of uPA (0-500 ng) and incubated in the wells of a conical bottom 96 -well plate for $60 \mathrm{~min}$ at $4^{\circ} \mathrm{C}$. At the end of incubation, $50 \mu \mathrm{l}$ of wash buffer containing saturating quantities (murine ascites or rabbit anti-serum) of the following antibodies-anti-Mo3f $\mathrm{mAb}(1 / 160), 5 \mathrm{~B} 7 \mathrm{mAb}(1 / 80)$, antiBMM1 mAb (1/80), polyclonal rabbit anti-sMo3 (antisMo3 pcAb) (1/40), or normal rabbit serum (1/40)—or $125 \mathrm{ng}$ uPA-FITC were added and the plate was incubated for an additional $60 \mathrm{~min}$ at $4^{\circ} \mathrm{C}$. The cells were then washed once with $200 \mu \mathrm{l}$ of wash buffer. The cells incubated with uPA-FITC were pelleted and resuspended in $200 \mu \mathrm{l}$ of PBS containing $1 \%$ formaldehyde. The cells incubated with monoclonal or polyclonal antibodies were pelleted and resuspended in $100 \mu \mathrm{l}$ of wash buffer containing either goat anti-mouse immunoglobulin (IgG) FITC (1:40 dilution) or goat antirabbit IgG FITC (1:60 dilution) and incubated for 30 min at $4^{\circ} \mathrm{C}$. These cells were washed three times with $200 \mu \mathrm{l}$ of wash buffer and resuspended in $200 \mu \mathrm{l}$ of wash buffer containing $1 \%$ formaldehyde. The relative binding of uPA-FITC, goat anti-mouse IgG FITC, or goat anti-rabbit IgG FITC was quantitated by flow cytometric analysis as described above.

Avidin-biotin enzyme immunoassay for the detection of soluble $u P A-R$. Immulon 4 microassay plates (Dynatech Laboratories, Inc., Chantilly, VA) were coated with $50 \mu \mathrm{l}$ of PBS containing $15 \mu \mathrm{g} / \mathrm{ml}$ of antiMo3f or anti-CD11b IgG for mAb capture, or $8 \mu \mathrm{l} / \mathrm{ml}$ of HMW or LMW uPA for ligand capture. After overnight incubation at $4^{\circ} \mathrm{C}$, the wells were blocked for $2 \mathrm{hr}$ at room temperature with $200 \mu \mathrm{l} /$ well of diluent buffer (PBS containing 5\% dry milk, $0.05 \%$ Tween 20 , and $0.01 \%$ Thimerosal). After washing five times with a copious amount of $0.9 \% \mathrm{NaCl}$ containing $0.05 \%$ Tween (a process that was repeated after each subsequent step), 50- $\mu$ l aliquots of diluent buffer containing known amounts of sMo3 or sr-uPA-R were added to the wells and incubated overnight at $4^{\circ} \mathrm{C}$. This was followed by two consecutive 2-hr incubations at room temperature with $50 \mu \mathrm{l}$ diluent buffer containing $0.5 \mu \mathrm{g} / \mathrm{ml}$ of antisMo3 rabbit IgG (which had been extensively precleared on plates coated with a mixture of anti-Mo3f and anti-CD $11 \mathrm{~b}$ IgG) and then $0.5 \mu \mathrm{g} / \mathrm{ml}$ of goat antrabbit IgG-biotin conjugate. Subsequently, the wells were incubated for $1 \mathrm{hr}$ at room temperature with $50 \mu \mathrm{l}$ diluent buffer containing $1 \mu \mathrm{g} / \mathrm{ml}$ of streptavidinHRPO. Finally, after washing, $50 \mu \mathrm{l}$ of substrate buffer

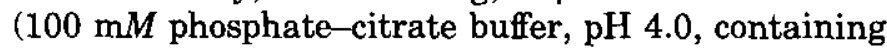
$0.05 \%$ Tween 20 ) containing $0.2 \mathrm{mg} / \mathrm{ml}$ of 2,2 -azino-bis (3-ethylbenzthiazoline-6-sulfonic acid) and $0.003 \%$ $\mathrm{H}_{2} \mathrm{O}_{2}$ was added to each well and incubated for $40 \mathrm{~min}$ at room temperature. Color development was then measured at $405 \mathrm{~nm}$ in a microplate reader (THERMOmax, Molecular Devices, Menlo Park, CA).

Immunoperoxidase staining of human tumor biopsy specimens. Formalin-fixed, paraffin-embedded tissue "sausages" containing different samples of prostatic cancer and breast tissues were obtained commercially (BioGenex, San Ramon, CA).

Immunoperoxidase staining was performed using the avidin-biotin-peroxidase complex (ABC) method as previously described (34). Briefly, permanent sections were deparaffinized and rehydrated through ethanol to water. Sections were then blocked and stained with primary antibodies that included anti-Mo3f, KJ23 (mouse mAb negative control), and EMA (mouse $\mathrm{mAb}$ specific for epithelial membrane antigen expressed by prostate and breast cancers). Negative control antibody was tested with each tissue, and at least one positive control was included in each experiment. After incubation with primary antibody overnight at $4^{\circ} \mathrm{C}$, the slides were washed in PBS and incubated for 1 $\mathrm{hr}$ with biotinylated horse anti-mouse antibody using reagents from the Vectastain $\mathrm{ABC}$ kit (Vector Labs, Burlingame, CA). The slides were then washed with PBS and treated with $0.3 \%$ peroxide in methanol for 30 min to inactivate endogenous peroxidase. After wash- 
ing in PBS, the sections were treated with avidinbiotin-peroxidase complex for $30 \mathrm{~min}$ and washed in PBS. The peroxidase reaction was developed with diaminobenzidine with $0.03 \%$ peroxide, resulting in a dark brown precipitate at the site of antibody localization. The sections were counterstained in hematoxylin and evaluated by light microscopy.

\section{RESULTS}

The results of previous experiments indicated that anti-Mo3f $\mathrm{mAb}$ recognized an epitope of uPA-R expressed by PMA-stimulated U-937 cells and COS cells transiently transfected with the Mo3 cDNA (19). We have extended these findings by the development of several NIH-3T3 murine fibroblast cell lines that, after calcium phosphate transfection, stably express the Mo3f epitope as measured by indirect immunofluorescence (Fig. 1). When these lines, along with PMAstimulated U-937 cells, were preincubated with a saturating quantity of anti-Mo3f mAb, the capacity of these cells to bind to FITC-conjugated UPA ligand (UPA-FITC) was reduced with the level of inhibition produced by anti-Mo3f mAb comparable to that caused by a saturating concentration of unlabeled uPA (Fig. 2). These results further support the concept that the Mo3f epitope is proximate to or lies within the ligandbinding domain (domain 1) of uPA-R.

To determine if there is a parallel crosscompetition between $\mathrm{mAb}$ and $\mathrm{uPA}$ for the ligand-binding domain of uPA-R, PMA-stimulated U-937 cells were either acid-washed [under conditions that dissociate endogenously bound UPA (35)] or sham-washed and then preincubated in buffer containing the indicated quantities of native HMW uPA (Fig. 3). Saturating quantities of anti-Mo3f or 5B7 mAb (the latter recognizing an irrelevant antigen expressed by U-937 cells) or polyclonal rabbit anti-sMo3 antiserum (anti-sMo3 pcAb) were

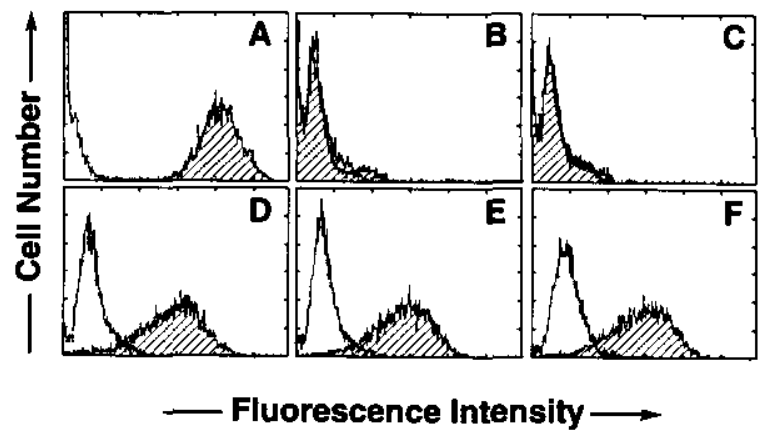

FIG. 1. Specific binding of anti-Mo3f $\mathrm{mAb}$ to uPA-R expressing NIH-3T3 transfectants. PMA-stimulated U-937 cells (A), NIH-3T3 wild type (B), NIH-3T3 uPA-R-negative transfectant 3T3-21 (C), and uPA-R expressing transfectants 3T3-1 (D), 3T3-2 (E), and 3T3-3 (F) were subjected to indirect immunofluorescence staining by anti-Mo3f $\mathrm{mAb}$ (hatched histograms) or with an isotype-matched irrelevant control mAb (anti-CD11b) (open histograms) and analyzed by flow cytometry.

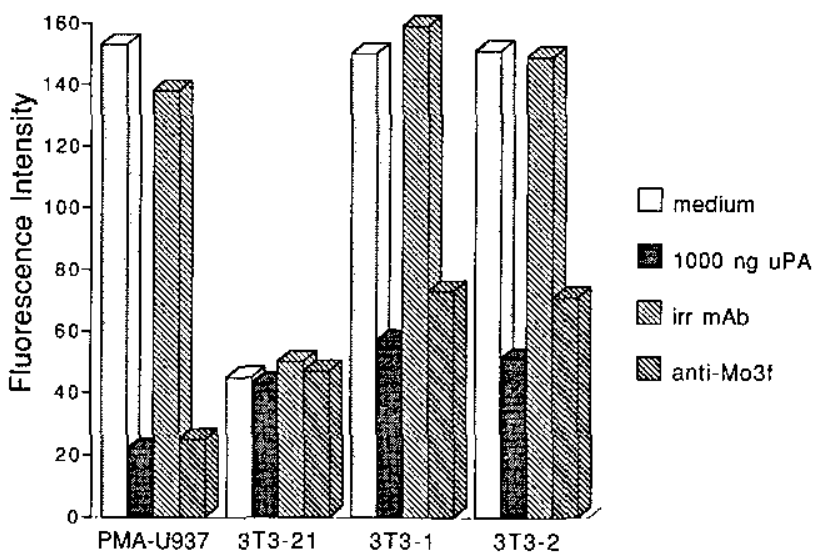

FIG. 2. Inhibition of uPA-FITC binding to uPA-R by anti-Mo3f mAb. PMA-stimulated U-937 cells, NIH-3T3 uPA-R-negative transfectant 3T3-21, or uPA-R expressing transfectants 3T3-1 and 3T3-2 were preincubated with either medium alone, $1000 \mathrm{ng}$ unlabeled uPA, or a saturating concentration of either irrelevant isotypematched (anti-CD11b) or anti-Mo3f mAb. uPA-FITC (125 ng/well) was then added to each sample and the cells were further incubated. The samples were washed and the relative amount of uPA-FITC bound (fluorescence intensity) was measured by flow cytometry. Similar results were seen in two other experiments.

added. After washing, the quantities of monoclonal or polyclonal antibodies bound to the uPA pretreated cells were determined by quantitative indirect immunofluorescence. Acid washing of U-937 cells had no significant effect on the subsequent binding of either monoclonal or polyclonal anti-Mo3 antibody (data not shown). Preincubation of U-937 cells in saturating

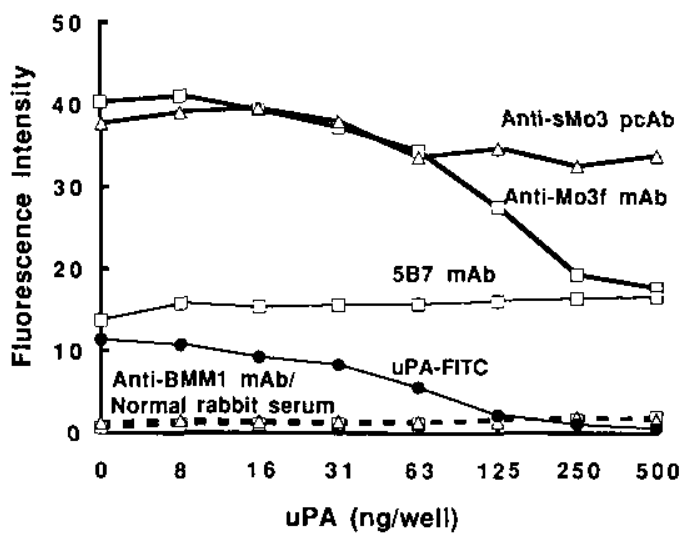

FIG. 3. Effect of uPA-R ligand occupancy on anti-Mo3f $\mathrm{mAb}$ binding. PMA-stimulated U-937 cells ("sham-washed") were preincubated in buffer containing the indicated quantities of native HMW uPA prior to a second incubation in buffer containing anti-Mo3f $\mathrm{mAb}$, anti-BMM1 $\mathrm{mAb}$ (isotype-identical negative control $\mathrm{mAb}$ ), $5 \mathrm{~B} 7 \mathrm{mAb}$ (isotype-identical positive control $\mathrm{mAb}$ ), anti-sMo3 pcAb, normal rabbit serum, or UPA-FITC. The effect of uPA preincubation on UPA-FITC binding was directly assessed by direct flow cytometric analysis, whereas the binding of $\mathrm{mAb}$ or pcAb reagents was assessed indirectly using appropriate FITC-conjugated anti-globulin reagents as described under Materials and Methods. Similar results were seen in four other experiments. Acid washing of PMA-stimulated U-937 cells prior to the binding assay did not alter the results observed (data not shown). 

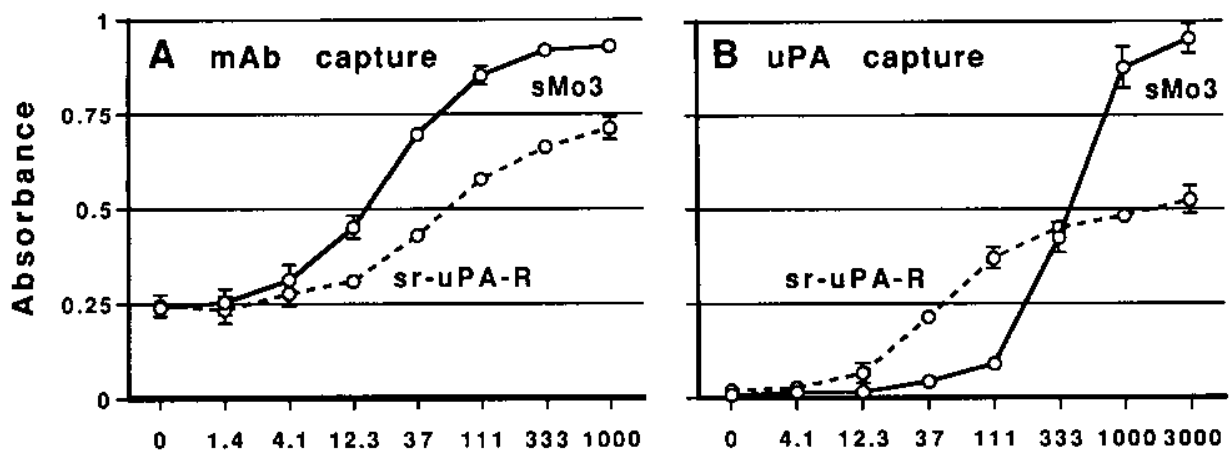

Soluble UPA-R, $\mathrm{ng} / \mathrm{mI}$

FIG. 4. Detection of soluble uPA-R by avidin-biotin enzyme immunoassay with mAb (A) and uPA (B) as capture. Buffer containing the indicated amounts of either sMo3 or sr-uPA-R was added to triplicate wells of Immulon 4 plates that had been precoated with anti-Mo3f mAb or anti-CD11b mAb (A), or HMW or LMW uPA (B). Bound UPA-R was detected by anti-sMo3 rabbit pcAb and then goat anti-rabbit IgG-biotin conjugate followed by streptavidin-HRPO. After 40 min incubation with the color development reagent, the plates were read at $405 \mathrm{~nm}$. The absorbance values shown represent specific uPA-R bound in which nonspecific uPA-R binding to either anti-CD11b (A) or LMW uPA (B) was subtracted from uPA-R bound to anti-Mo3f or HMW uPA, respectively. Similar results were seen in two other experiments.

quantities of exogenous uPA (500 ng/well; sufficient to prevent the binding of uPA-FITC) partially inhibited the binding of anti-Mo3f mAb (by a mean \pm SD of 69.9 $\pm 7.0 \%, n=3$ ) but caused minimal reduction in polyclonal antibody binding $(8.1 \pm 7.6 \%$ inhibition, $n=3)$. These data further localized the Mo3 epitope to the ligand-binding domain of uPA-R.

Soluble forms of uPA-R have been isolated by $\mathrm{mAb}$ or a ligand affinity purification from (a) supernatants of PMA-stimulated U-937 cells treated with phosphatidylinositol-specific phospholipase C (PI-PLC) (with the release of PI-linked glycoproteins) $(18,19)$, or (b) culture media of cell lines transfected with uPA-R cDNA mutagenized so as to secrete recombinant uPA-R (this report and 36). ELISAs have been developed so as to quantitate these soluble forms of uPA-R. In Figs. 4A and $4 \mathrm{~B}$, immobilized anti-Mo3f mAb and HMW uPA were employed as the uPA-R "capture" reagents, respectively. In both assays, rabbit anti-sMo3 polyclonal antibody served as the detection reagent whose binding to captured uPA-R was quantitated by secondary antibody-biotin conjugate and streptavidin-HRPO
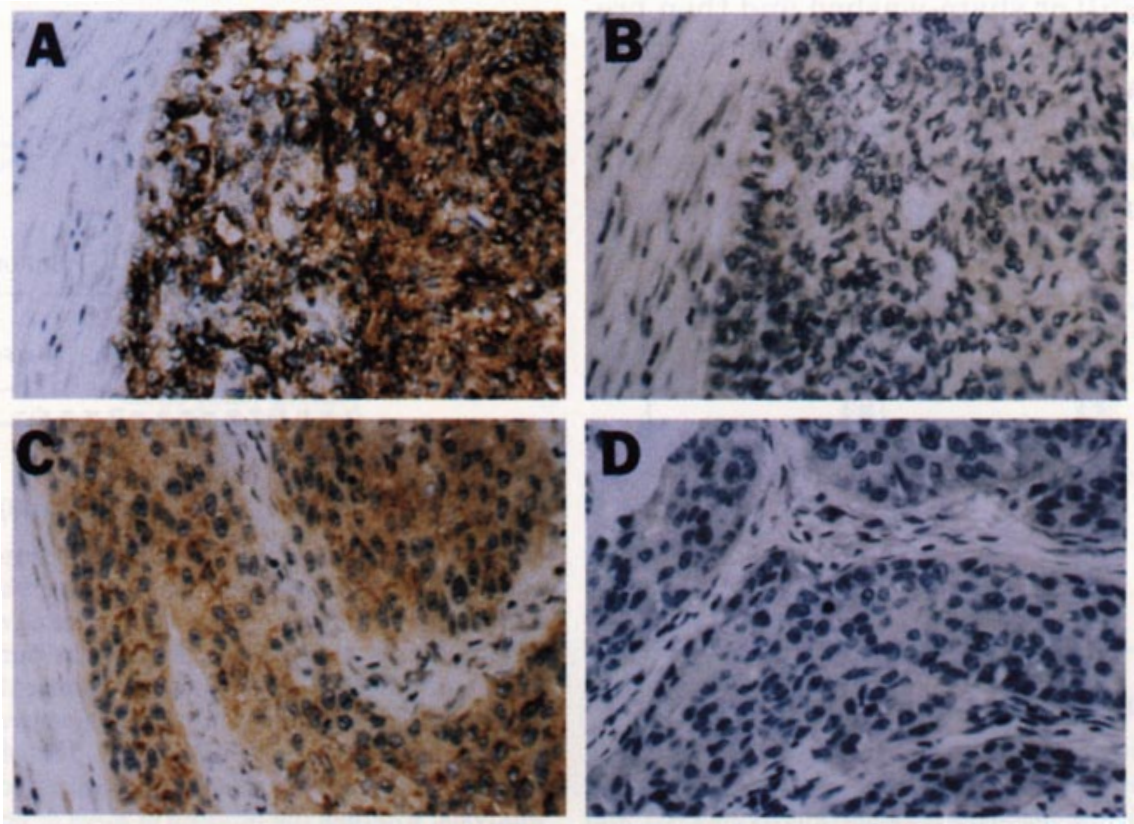

FIG. 5. Immunoperoxidase staining for the expression of UPA-R in tumor biopsy specimens using anti-Mo3f mAb. Sections of formalinfixed paraffin-embedded tissue "sausages" containing specimens of breast and prostatic tumor tissue were subjected to immunoperoxidase staining as described under Materials and Methods. (A) Prostatic carcinoma stained with anti-Mo3f mAb; (B) prostatic carcinoma (same tissue as in A) stained with negative control mAb, KJ23; (C) breast carcinoma stained with anti-Mo3f mAb; (D) breast carcinoma (Same tissue as in C) stained with KJ23. All sections were counterstained with hematoxylin. 
(Materials and Methods). The data shown in Figs. 4A and $4 \mathrm{~B}$ represent specific $\mathrm{UPA}-\mathrm{R}$ detection in which nonspecific uPA- $R$ binding to an isotype-identical nonreactive murine $\mathrm{mAb}$ (Fig. 4A) and LMW uPA (lacking the receptor-binding domain) (Fig. 4B) were subtracted from the absorbance values representing uPA-R bound to anti-Mo3f mAb and HMW, uPA, respectively. These assays have a sensitivity of detection of approximately 4-12 $\mathrm{ng} / \mathrm{ml}$ for the Mo3f epitope and 37-111 $\mathrm{ng} / \mathrm{ml}$ for ligand-binding UPA-R.

uPA binds to uPA-R expressed by certain tumor cells and the extent of uPA binding has been correlated with invasive potential (4-10). To determine if anti-Mo3f $\mathrm{mAb}$ can be used to detect the expression of $\mathrm{UPA}-\mathrm{R}$ by human tumor tissues, biopsy specimens containing breast and prostate carcinoma were examined for specific binding of anti-Mo3f mAb using a conventional $\mathrm{ABC}$ immunoperoxidase assay. Among 16 breast and 31 prostate carcinoma specimens examined in this way, positive tumor cell staining was observed in 4 and 7 , respectively. Representative examples of positively stained specimens are shown in Fig. 5 which demonstrates uniform expression of the Mo3f epitope by the majority of tumor cells within each specimen. Because these tumor tissues contain relatively few stromal or infiltrating inflammatory cells, no definitive conclusions can be drawn about uPA-R expression by nonmalignant cells.

\section{DISCUSSION}

Over the past 2 years, major progress has been made in the molecular characterization of the uPA-R. Most significantly, this receptor has been cloned and recombinantly expressed by two groups: first by Roldan and colleagues ( 31 ) who set out to extend their preliminary biochemical characterization of uPA-R $(20,37,38)$, and then by our laboratory which found that the nucleotide sequence of a cDNA encoding for the Mo3 phagocyte activation antigen $(17,18,39-42)$ was nearly identical to that encoding for uPA-R (19). In our work, the cloning of $U P A-R$ was made possible by our earlier development of $\mathrm{mAb}$ anti-Mo3f (17), which enabled us to purify the Mo3 glycoprotein from cellular extracts that preserve the conformational integrity of the receptor ${ }^{3}$ (either nondenaturing detergent lysates or PI-PLC releasates) $(17,18)$. Using affinity chromatography, we were able to recover Mo3 glycoprotein (at least $95 \%$ homogeneous by high-performance liquid chromatography) from the supernatants of PI-PLC-treated, PMA. stimulated U-937 cells at a yield of $10 \mu \mathrm{g} / 10^{8}$ cells (18). This antibody affinity-purified material was subjected

\footnotetext{
${ }^{3}$ Anti-Mo3f mAb does not detect uPA-R in Western blotting suggesting that the epitope is conformationally sensitive.
}

to amino acid and carbohydrate analysis-providing important insights with respect to glycoprotein composition (18)-and internal amino acid sequencing (19). The resultant construction of "guessmer" oligonucleotides based upon empiric amino acid sequence then led to our successful screening and identification of a fulllength Mo3 complementary DNA (cDNA) that, to our surprise, matched the open reading frame of the UPA-R cDNA cloned by Roldan et al. $(19,31)$.

Having thus established that anti-Mo3f recognizes uPA-R, in this report we extend our characterization of the epitope with respect to the ligand-binding domain. Our competitive binding studies support the notion that the Mo3f epitope is contained within or proximate to the binding site for uPA: anti-Mo3f blocked the cellular binding of exogenously added uPA. The question then arose as to whether crosscompetition could occur, i.e., whether anti-Mo3f could bind to occupied as well as unoccupied uPA-R. Under conditions of ligand saturation (as documented by complete inhibition of uPAFITC binding), partial inhibition of anti-Mo3f $\mathrm{mAb}$ was observed but not to the extent that ligand occupancy completely masked mAb recognition. The possibility that this quantitative reduction in anti-Mo3f binding to ligand-treated cells is due to receptor internalization or shedding as opposed to competitive inhibition is excluded by control experiments in which the binding of polyclonal anti-sMo3 antibody was not significantly affected by ligand presaturation. Subsaturating quantities of bound ligand (either endogenous or exogenous) resulted in little or no competition.

Applications for the use of anti-Mo3f mAb include the development of a sensitive ELISA to measure the concentration of $u P A-R$ in soluble form. Such an assay would be useful in determining the yield of uPA-R isolated by affinity chromatography from cellular sources (e.g., from PI-PLC releasates or secreted recombinant material) for subsequent biochemical and functional analyses. As shown in Fig. 4, anti-Mo3f can serve as an effective capture reagent in an ELISA that is comparable in its sensitivity and specificity to a ligand capture ELISA in which the same polyclonal anti-uPA-R antibody is employed as the detection reagent. The current availability of these ELISAs makes it possible to determine if soluble forms of uPA-R exist in vivo [e.g., in sera or other body fluids) as has been demonstrated in the sera of patients with paroxysmal nocturnal hemoglobinuria (43) etc.] (44-46). The results of preliminary analyses indicating the presence of soluble UPA- $R$ in certain inflammatory exudates (Mizukami and Todd, unpublished observations) raises the possibility that $U P A-R$ may represent a serologically detectable marker of inflammation.

Another application of anti-Mo3f mAb as a serological probe for uPA-R expression is its use in detecting uPA-R associated with tumor tissues. The fact that the Mo3f epitope is stable to standard tissue fixation 
makes it ideal as a tool for examining formalin-fixed, paraffin-embedded tumor specimens. Among the 47 specimens of breast and prostate carcinoma examined by conventional immunoperoxidase staining, $11(4 / 16$ breast and $7 / 31$ prostate cancers) demonstrated unequivocal tumor cell staining. With respect to breast carcinoma cell expression of $\mathrm{UPA}-\mathrm{R}$, similar results have recently been reported by Chucholowski et al. (47) and Del Vecchio et al. (48) who observed positive antiMo3f mAb (American Diagnostica antibody 3936) staining of fixed breast carcinoma cell lines and frozen biopsy specimens, respectively. In the latter study, antibody binding was consistent with the enhanced levels of radioligand binding to the same carcinoma tissues. Our observations differ from those of Del Vecchio et al. in that we observed heterogeneity of breast carcinoma $\mathrm{mAb}$ staining (25\% positive staining among 16 specimens), whereas they reported uniform uPA-R expression among all 22 specimens examined. Consistent with our results, Pyke et al. (49), using a different antiuPA-R mAb (R2; see below), observed breast carcinoma cell staining in only 5 of 34 fixed, paraffinembedded specimens. The discrepancy between our observations and those of Del Vecchio et al. might be explained by the fact that in their study, frozen biopsy sections were acid-washed prior to fixation so as to dissociate endogenously bound uPA ligand, which, as shown in Fig. 3, might compete for anti-Mo3f mAb binding to UPA-R. However, this explanation should not account for the heterogeneity observed by Pyke et $a l$. since the mAb employed in their study, R2, is said to recognize $u P A-R$ that is occupied by ligand (21). A direct comparison between $\mathrm{R} 2$ and anti-Mo3f for recognition of uPA-R on a larger number of breast biopsy specimens (approximately 650 cases) is currently in progress [conducted by Dr. Daniel Ciocca (Mendoza, Argentina), in collaboration with Drs. Kent Osborne (San Antonio, TX), Nils Brunner (Copenhagen, Denmark), and Robert Todd (Ann Arbor, MI)] and may shed more light on the extent of heterogeneity of uPA-R expression among breast carcinomas and the degree to which receptor occupancy influences the detection of uPA-R by anti-Mo3f.

Other monoclonal antibodies that detect $u P A-R$ have recently been generated by at least three other laboratories. Ronne et al. from the Finsen Laboratory have reported the development of four reagents $(R 1, R 2, R 3$, and R4) that recognize distinct epitopes $(21,50)$. Most similar to anti-Mo3f is antibody R3, which binds to a ligand-binding $16 \mathrm{kDa}$ amino terminus fragment of uPA-R (51) and blocks both uPA binding and cellular uPA-dependent plasminogen activation (21). Antibodies R2 and R4, on the other hand, do not bind to the amino terminal fragment and do not inhibit receptorligand interaction. These data indicate that the R3 epitope-like the anti-Mo3f epitope-is proximate to the ligand-binding domain of UPA-R, while the R2 and
R4 epitopes are functionally inert. Other antibodies recognizing functional uPA-R epitopes have been developed by Knapp and colleagues (antibody VIM-5) (52, W. Knapp, personal communication) and Binder $e t$ al. (B. Binder, personal communication). A direct comparison of many of these anti-uPA-R reagents, including their potential use in receptor epitope mapping, was the focus of a uPA-R antibody workshop under the auspices of the recent Fifth International Workshop and Conference on Human Leukocyte Differentiation Antigens. As a consequence of this workshop, certain anti-uPA-R mAb (including anti-Mo3f and VIM-5) were given the cluster designation CD87 (53).

\section{ACKNOWLEDGMENTS}

The authors thank Kristine L. Weber for her help in flow cytometry, Tracy L. Goetz for her assistance in the preparation of the manuscript, Dr. Suyu Shu (University of Michigan) for his gift of control mAb, KJ23, and Dr. Richard Hart (American Diagnostica, Inc.) for his gifts of urokinase reagents.

\section{REFERENCES}

1. Ploug, M., Behrendt, N., Lober, D., and Dano, K., Protein structure and membrane anchorage of the cellular receptor for urokinase-type plasminogen activator. Semin. Thromb. Hemostas. 17, 183-193, 1991.

2. Ellis, Z., and Dano, K., The urokinase receptor and the regulation of cell surface plasminogen activation. Fibrinolysis 6, 2734.

3. Ellis, V., Behrendt, N., and Dano, K., Plasminogen activation by receptor-bound urokinase: A kinetic study with both cell-associated and isolated receptor. J. Biol. Chem. 226, 12752-12758, 1991.

4. Hollas, W., Blasi, F., and Boyd, D., Role of the urokinase receptor in facilitating extracellular matrix invasion by cultured colon cancer. Cancer Res. 51, 3690-3695, 1991.

5. Markus, G., The relevance of plasminogen activators to neoplastic growth. A review of recent literature. Enzyme 40, 158-172, 1988.

6. Ossowski, L., In vivo invasion of modified chorioallantoic membrane by tumor cells: The role of cell surface-bound urokinase. $J$. Cell Biol. 107, 2437-2445, 1988.

7. Schlehte, W., Murano, G., and Boyd, B., Examination of the role of the urokinase receptor in human colon cancer mediated laminin degradation. Cancer Res. 49, 6064-6069, 1989.

8. Kirchheimer, J. C., and Remold, H. G., Endogenous receptorbound urokinase mediates tumor invasion of human monocytes. J. Immunol. 143, 2634-2639, 1989.

9. Bruckner, A., Filderman, A. E., Kirchheimer, J. C., Binder, B. R., and Remold, H. G., Endogenous receptor-bound urokinase mediates tissue invasion of the human lung carcinoma cell lines A549 and Calu-1. Cancer Res. 52, 3043-3047, 1992.

10. Cohen, R. L., Zxi, X-P., Crowley, C. W., Lucas, B. K., Levinson, A. D., and Schuman, M. A., Effects of urokinase receptor occupancy on plasmin generation and proteolysis of basement membrane by human tumor cells. Blood 78, 479-487, 1991.

11. Vassalli, J. D., Sappino, A. P., and Belin, D., The plasminogen activator/plasmin system. J. Clin. Invest. 88, 1067-1072, 1991.

12. Kobayashi, H., Ohi, H., Sugimura, M., Shinohara, H., Fujii, T., and Parao, T., Inhibition of in vitro ovarian cancer cell invasion by modulation of urokinase-type plasminogen activator and cathespin B. Cancer Res. 52, 3610-3614, 1992.

13. Mignatti, P., Robbins, E., and Rifkín, D. B., Tumor invasion 
through the human amniotic membrane: Requirement for a proteinase cascade. Cell 47, 487-498, 1986.

14. Ossowski, L., and Reich, E., Antibodies and plasminogen activator inhibit human tumor metastasis. Cell 35, 611-619, 1983.

15. Hearing, V. J., Law, L. W., Corti, A., Appella, E., and Blasi, F., Modulation of metastatic potential by cell surface urokinase of murine melanoma cells. Cancer Res. 48, 1270-1278, 1988.

16. Meissauer, A., Kramer, M. D., Hofmann, M., Erkell, L. J., Jacob, E., Schirrmacher, V., and Brunner, G., Urokinase-type and tissue-type plasminogen activators are essential for in vitro invasion of human melanoma cells. Exp. Cell. Res. 192, 453-459, 1991.

17. Mizukami, I. F., Vinjamuri, S. D., Trochelman, R. D., and Todd, R. F. III., A structural characterization of the Mo3 activation antigen expressed on the plasma membrane of human mononuclear phagocytes. J. Immunol. 144, 1841-1848, 1990.

18. Mizukami, I. F., Vinjamuri, S. D., Perini, F., Liu, D. X., and Todd, R. F. III., Purification, biochemical composition, and biosynthesis of the Mo3 activation antigen expressed on the plasma membrane of human mononuclear phagocytes. J. Immunol. 147, 1331-1337, 1991.

19. Min, H. Y., Semnani, R., Mizukami, I. F., Watt, K., Todd, R. F., III. and Liu, D. Y., cDNA for Mo3, a monocyte activation antigen, encodes the human receptor for urokinase plasminogen activator. J. Immunol. 148, 3636-3642, 1992.

20. Behrendt, N., Ronne, E., Ploug, M., Petri, T., Lober, D., Nielsen, L. S., Schleuning, W-D., Blasi, F., Appella, E., Dano, K., The human receptor for urokinase plasminogen activator. $\mathrm{NH}_{2}$ terminal amino acid sequence and glycosylation variants. $J$. Biol. Chem. 265, 6453-6460, 1990.

21. Ronne, E., Behrendt, N., Ellis, V., Ploug, M., Dano, K., and Hoyer-Hansen, G., Cell-induced potentiation of the plasminogen activation systems as abolished by monoclonal antibody that recognizes the $\mathrm{NH}_{2}$-terminal domain of the urokinase receptor. FEBS Lett. 288, 233-236, 1991.

22. Kwaan, H. C., and Keer, H. N., Fibrinolysis and cancer. Semin. Thromb. Hemost. 16, 230-235, 1990.

23. Graeff, H., Harbeck, N., Pache, L., Wilhelm, O., Janick, E. F., and Schmitt, M., Prognostic impact and clinical relevance of tumor-associated proteases in breast cancer. Fibrinolysis 6,45 54, 1992.

24. Duffy, M. J., Reilly, D., Nolan, N., O'Higgins, N., Fennelly, J. J., and Andreasen, T., Urokinase plasminogen activator, a strong and independent prognostic marker in breast cancer. Fibrinoly. sis 6, 55-58, 1992.

25. Oka, T., Ishida, T., Nishimo, $T$., and Sugimachi, K., Immunohistochemical evidence of urokinase-type plasminogen activator in primary and metastatic tumors of pulmonary adenocarcinoma. Cancer Res. 51, 3522-3525, 1991.

26. Pyke, C., Kristensen, T., Ralfkifr, E., Grondahl-Hansen, J., Eriksen, J., Blasi, F., and Dano, K., Urokinase-type plasminogen activator is expressed in stromal cells and its receptor in cancer cells at invasive foci in human colon adenocarcinomas. Am. J. Pathol. 138, 1059-1067, 1991.

27. Biondi, A., Rossing, T. H., Bennett, J., and Todd, R. F., III., Surface membrane heterogeneity among mononuclear phagocytes. J. Immunol. 132, 1237-1243, 1984.

28. Dana, N., Styrt, B., Griffin, J. D., Todd, R. F., III, Klempner, M. S., and Arnaout, M. A., Two functional domains in the phagocyte membrane glycoprotein Mo1 identified with monoclonal antibodies. J. Immunol. 137, 3259-3263, 1986.

29. Kappler, J. W., Roehm, N., and Marrack, P., T cell tolerance by clonal elimination in the thymus. Cell 49, 273-280, 1987.

30. Sloane, J. P., and Ormerod, M. G., Distribution of epithelial membrane antigen in normal and neoplastic tissues and its value in diagnostic tumor pathology. Cancer 47, 1786-1795, 1981.

31. Roldan, A., Cubellis, M. V., Masucci, M. T., Behrendt, N., Lund, L. R., Dano, K., Appella, E., and Blasi, F., Cloning and expression of the receptor for human urokinase plasminogen activator, an essential molecule in cell surface, plasminogen-dependent proteolysis. EMBO. J. 9, 467-474, 1990.

32. Sambrook, J., Fritsch, E. F., and Maniatis, T., Molecular Cloning, A Laboratory Manual, Cold Spring Harbor Press, Cold Spring Harbor, NY, 1989.

33. Southern, P. J., and Berg, P., Transformation of mammalian cells to antibiotic resistance with a bacterial gene under control of the SV40 early region promoter. J. Mol. Appl. Genet. 1, 327$341,1982$.

34. Hsu, S. M., Raine, L., and Fanger, H., Use of avidin-biotinperoxidase complex $(A B C)$ in immunoperoxidase techniques: $A$ comparison between $\mathrm{ABC}$ and unlabeled antibody (PAP) procedures. J. Histochem. Cytochem. 29, 577-580, 1981.

35. Stoppelli, M. P., Tacchetti, C., Cubellis, M. V., Corti, A., Hearing, V. J., Cassani, G., Appella, E., and Blasi, F., Autocrine saturation of pro-urokinase receptors on human A431 cells. Cell 45, 675-684, 1986.

36. Masucci, M. T., Pedersen, N., and Blasi, F., A soluble, ligand binding mutant of the human urokinase plasminogen activator receptor. J. Biol. Chem. 266, 8655-8658, 1991.

37. Stoppelli, M. P., Corti, A., Soffientini, A., Cassani, G., Blasi, F., and Assoian, R.K., Differentiation-enhanced binding of the amino-terminal fragment of human urokinase plasminogen activator to a specific receptor on U-937 monocytes. Proc. Natl. Acad. Sci. USA 82, 4939-4943, 1985.

38. Nielsen, L. S., Kellerman, G. M., Behrendt, N., Picone, R., Dano, $\mathrm{K}$., and Blasi, F., A 55,000-60,000 Mr receptor protein for urokinase-type plasminogen activator. Identification in human tumor cell lines and partial purification. J. Biol. Chem. 263, 2358-2363, 1988.

39. Todd, R. F., III, Alvarez, P. A., Brott, D. A., and Liu, D. Y., Bacterial lipopolysaccharide, phorbol myristate acetate, and muramyl dipeptide stimulate the expression of a human monocyte surface antigen, Mo3e. J.Immunol. 135, 3869-3877, 1985.

40. Todd, R. F., III, Bury, M. J., Alvarez, P. A., Brott, D. A., and Liu, D. Y., Regulation of human monocyte surface antigen expression. I. Up-modulation of Mo3e antigen expression on U-937 and HL-60 cells stimulated by pharmacological activators of protein kinase C. Blood 68, 1154-1161, 1986.

41. Liu, D. Y., and Todd, R. F., III., A monoclonal antibody specific for a monocyte-macrophage membrane component blocks the human monocyte response to migration inhibitory factor. J. $\mathrm{Im}$. munol. 137, 448-455, 1986.

42. Todd, R. F., III, Mizukami, I. F., Vinjamuri, S. D., Trochelman, R. D., Hancock, W. W., and Liu, D. Y., Human mononuclear phagocyte activation antigens. Blood Cells 16, 167-182, 1990.

43. Ploug, M., Eriksen, J., Plesner, T., Hansen, N. E., and Dano, K., A soluble form of the glycolipid-anchored receptor for urokinasetype plasminogen activator is secreted from peripheral blood leukocytes from patients with paroxymal nocturnal hemoglobinuria. Eur. J. Biochem. 208, 397-404, 1992.

44. Medof, M. E., Walter, E. I., Rutgers, J. L., Knowles, D. M., and Nussenzweig, V., Identification of the complement decayaccelerating factor (DAF) on epithelium and glandular cells and in body fluids. J. Exp. Med. 165, 848-864, 1987.

45. Fleit, H. B., Kobasiuk, C. D., Daly, C., Furie, R., Levy, P. C., and Webster, R. O., A soluble form of FcrRIII is present in human serum and other body fluids and is elevated at sites of inflammation. Blood 79, 2721-2728, 1992.

46. Grunwald, U., Kruger, C., Westermann, J., Lukowsky, A., Ehlers, M., and Shutt, C., An enzyme-linked immunosorbent 


\section{MIZUKAMI ET AL.}

assay for the quantification of solubilized CD14 in biological fluids. J. Immunol. Methods 155, 225-232, 1992.

47. Chucholowski, N., Schmitt, M., Rettenberger, P., Schuren, E., Moniwa, N., Goretzki, L., Wilhelm, O., Weidle, U., Janick, E. F., and Graeff, H., Flow cytometric analysis of the urokinase receptor (UPA-R) on tumor cells by fluorescent UPA-ligand or monoclonal antibody \#3936. Fibrinolysis 4, 95-102, 1992.

48. Del Vechio, S. D., Stoppelli, M. P., Carriero, M. V., Fonti, R., Massa, O., Li, P. Y., Botti, G., Cerra, M., D'Aiuto, G., Esposito, G., and Salvatore, M. Cancer Res. 53, 3198-3206., 1993.

49. Pyke, C., Graem, N., Ralfkiaer, E., Ronne, E., Hoyer-Hansen, G., Brunner, N., and Dano, K., Receptor for urokinase is present in tumor-associated macrophages in ductal breast carcinoma. Cancer Res. 53, 1911-1915, 1993.

50. Ploug, M., Plesner, T., Ronne, E., Ellis, V., Hoyer-Hansen, G., Hansen, N. E., and Dano, K., The receptor for urokinase-type plasminogen activator is deficient on peripheral blood leukocytes in patients with paroxysmal nocturnal hemoglobinuria. Blood 79, 1447-1454, 1992.

51. Behrendt, N., Ploug, M., Patthy, L., Houen, G., Blasi, F., and Dano, K., The ligand binding domain of the cell surface receptor for urokinase-type plasminogen activator. J. Biol. Chem. 266 , 7842-7847, 1991.

52. Gadd, S. J., Majdic, O., Casinrerk, W., Stockinger, H., Maurer, D., Eher, R., and Knapp, W., M5, a phosphoinositol-linked human myelomonocytic activation-associated antigen. Clin. Exp. Immunol. 80, 252-256, 1990.

53. Schlossman, S. F., Bournsell, L., Gilks, W., Harlan, J. M., Kishimoto, T., Morimoto, C., Ritz, J., Shaw, S., Silverstein, R. L., Springer, T. A., Tedder, T. F., and Todd, R. F., CD antigens 1993. J. Immunol. 152, 1-2, 1994.

Received August 13, 1993; accepted with revision December 13, 1993 